\title{
The Effects of Long -term Winter Swimming on Lipid and Hemorheology of Senile Males
}

\author{
Qinghong Xia \\ Dept. Preventive Medicine \\ Medicine College ,Anhui University of Science\&Techology \\ Huainan 232001, China \\ qinghongbenben@163.com
}

\author{
Rihui Zhang \\ Dept. Sports Human Science \\ Shenyang Institute of Physical Education \\ Shenyang 110102,China \\ rhzhang75@yahoo.com.cn
}

\author{
Zhiliang $\mathrm{Fu}$ \\ Dept. Mining \\ Energy \&Safety College, Anhui University of Science\&Techology \\ Huainan 232001, China \\ zhlfu@aust.edu.cn
}

\begin{abstract}
The objective is to discuss on influences of long-term winter swimming on hemorheology of Males (70-80 years old), which it can provide an experimental basis for scientific fitness of the elders in china by consulting health examination archives of subjects since 1998 , and then comparison and analysis of all lipid and hemorheology indexes were made. The whole-blood viscosity at low ,medium and high shear of winter swimming group ,the reduced viscosity of whole blood is lower than that of control group, viscosity of whole blood is higher than that of control group; There was no significance difference. Two groups of hematocrit means are equal. The plasma viscosity and erythrocyte sedimentation rate (ESR) of winter swimming group was obviously lower than those of the control group, there's obvious difference $(P<0.01)$. A long term winter swimming can reduce the blood plasma viscosity and erythrocyte sedimentation rate (ESR) of the male (45-55 year old), improve hemorheology characteristics.
\end{abstract}

Keywords- winter swimming; senile male; lipid; hemorheology

\section{INTRODUCTION}

Winter swimmers are a group of people who are daily exposed to a short cold shock. The aim of the present study was toinvestigate whether such people have accustomed themselves to prefer lower ambient temperatures than other people. The genetic epidemiological investigations indicate that incidence of lipid abnormality of elderly male tended to increase with the age. the vessel wall damage induced by lipid abnormality is easy to cause blood rheology abnormality, we call this Blood Hyperviscosity Syndrome (HVS). common geriatric diseases and frequent disease of the elderly ,such as arteriosclerosis, coronary disease, Cerebral Thrombosis and Myocardial Infarction and pulmonary heart disease, etc, may have a correlation with Blood Hyperviscosity Syndrome (HVS) and lipid abnormality.Some components, such as multi-leveled equations, graphics, and tables are not prescribed, although the various table text styles are provided.
The formatter will need to create these components, incorporating the applicable criteria that follow.

\section{SUBJECTS AND METHODS}

\section{A. Subjects}

The following groups of subjects were studied: winter swimmers (eight 70-80 years old men.) who had been exposed to cold shock every week by swimming in the water $\left(0-6^{\circ} \mathrm{C}\right)$ during the winter season about $1-8 \mathrm{~min}$, during the summer season about $20-60 \mathrm{~min}$ by swimming in the water $\left(10-15^{\circ} \mathrm{C}\right)$. All subjects had been winter swimmers for at least twenty years(the shortest Winter swimming age is 9 years, the average is $14.5 \mathrm{y}$,) and the experiments took place late in the winter season. Control group: who don' t often take part in physical training, are healthy, eight 70-80 years old men.

Subjects background :a. Cardiopulmonary Functions is normal ; b. no-hyperlipidemic type 2 diabetes mellitus,hypercholesterolemia, non-diabetics; c. blood pressure is normal or older persons with mild hypertension (blood pressure $\leqslant 160 / 95 \mathrm{mmHg}$ ) .

Table 1. Subjects characteristics

\begin{tabular}{ccccc}
\hline group & age & height $(\mathrm{cm})$ & weight $(\mathrm{kg})$ & BMI \\
& $(\mathrm{y}$ & & & \\
& & & & \\
& & & & \\
\hline Winter & 73.38 & $171.25 \pm$ & $67.13 \pm$ & $22.89 \pm 1.48$ \\
swimming $(\mathrm{n}=8)$ & \pm & 6.30 & 5.89 & \\
& 2.13 & & & \\
& & & & \\
\hline
\end{tabular}




$\begin{array}{ccccc}\text { Control group } & 72.87 & 170.13 \pm & 66.50 \pm & 22.95 \pm 1.03 \\ (\mathrm{n}=8) & \pm & 5.08 & 5.98 & \\ & 2.17 & & & \\ & & & \end{array}$

note: as compared with control group $* \mathrm{p}<0.05 * * \mathrm{p}<0.01$.

\section{B. Methods}

All subjects have no swimming two days before blood sampling,. All subjects can not eat high fat food One day before blood sampling, tomorrow morning after 12 hours fasting, $5 \mathrm{ml}$ blood was drawn from elbow vein ;(a) 4ml Blood samples from elbow vein were collected,and to separate serum immediately, used for blood lipid test (b) $4 \mathrm{ml}$ venous blood was injected into vacuum test tubes, which contain Heparin Anticoagulant; no hemolytic reaction, blood samples were stored in constant temperature water bath at $37^{\circ} \mathrm{C}$, used for blood rehology test; index testing must be taken after blood collecting in 4 hours. Statistics differences among groups were analyzed for statistical significance by ANOVA, followed by Student's t-test to determine $p$ values. The results were analyzed by the statistical software SPSS 12.0 .Differences among groups were compared with $t$ test.

\section{Main reagents and instruments}

TG(Triglyceride), TC(total cholesterol), HDL-CH(high density lipoprotein cholesterol) and LDL-CH(low density lipoprotein cholesterol) Kits are made from KHB, operation are made strictly in accordance with the kit's requirements; test instrument include TBA-40FR automatic biochemical analyzer, FASCO-3010Automatic Hemorheological Analyser.

\section{EXPERIMENTAL RESULTS}

\section{A. Long term winter swimming have influence on $T C 、 T G$}

According to experiments results in table1, we can make some conclusions that TC,TG and LDL-CH in winter swimming group are lower than those of control group , TC、LDL-CH of winter swimming group has significant difference compared with control group $(\mathrm{P}<0.05)$, There was significant difference between the groups in TG $(\mathrm{P}<0.01)$,HDL-CH in winter swimming group is higher than that of control group, the difference was very significant $(\mathrm{P}<0.01)$.

Table 2 Index comparison of between two groups

in TG、TC、HDL-CH and LDL-CH

\begin{tabular}{lllll}
\hline group & TG & TC & HDL-CH & LDL-CH \\
\hline Winter & $1.03 \pm 0.26$ & $4.68 \pm 0.44$ & $1.45 \pm 0.17$ & $3.00 \pm 0.21$ \\
swimming & $* *$ & $*$ & $* *$ & $*$ \\
Control & $1.37 \pm 0.14$ & $5.23 \pm 0.34$ & $1.18 \pm 0.12$ & $3.33 \pm 0.25$ \\
group & & & & \\
\hline
\end{tabular}

Note: as compared with control group $* \mathrm{p}<0.05 * * \mathrm{p}<0.01$

\section{B. The index change of blood rheology of two groups}

The whole blood viscosity (higher, middle and lower high or low shear rate) in winter swimming group, blood viscosity, whole blood reducing viscosity (higher, middle and lower high or low shear rate). hematocrit HCT is lower than those in control group,there was no significant difference .both plasma viscosity and erythrocyte sedimentation rate (ESR) in winter swimming group are lower significantly than that of control group, the difference between treatment groups at week 52 was very significant $(\mathrm{P}<0.01)$.Results The data show that T,E_2 and the ratio of T/E_2 in the winter swimming group were much higher than that of the control group

Table 3 index comparison of blood rheology

\begin{tabular}{|c|c|c|}
\hline index & $\begin{array}{l}\text { experiment } \\
\text { Group }\end{array}$ & control group \\
\hline $\begin{array}{l}\text { High shear-rate of total blood } \\
\text { viscosity }(200 / \mathrm{s})\end{array}$ & $5.05 \pm 0.53$ & $5.31 \pm 0.37$ \\
\hline $\begin{array}{l}\text { middle shear-rate of total blood } \\
\text { viscosity }(30 / \mathrm{s})\end{array}$ & $6.21 \pm 0.64$ & $6.36 \pm 0.42$ \\
\hline $\begin{array}{l}\text { Low shear-rate of total blood } \\
\text { viscosity }(3 / \mathrm{s})\end{array}$ & $12.74 \pm 0.67$ & $13.20 \pm 0.74$ \\
\hline Plasma viscosity & $1.42 \pm 0.08 * *$ & $1.63 \pm 0.11$ \\
\hline Hematocrit(HCT) & $0.45 \pm 0.02$ & $0.46 \pm 0.03$ \\
\hline $\begin{array}{l}\text { High shear-rate of total blood } \\
\text { reductive viscosity }(200 / \mathrm{s})\end{array}$ & $4.96 \pm 0.68$ & $5.02 \pm 0.66$ \\
\hline $\begin{array}{l}\text { middle shear-rate of total blood } \\
\text { reductive viscosit }(30 / \mathrm{s})\end{array}$ & $6.57 \pm 0.88$ & $6.67 \pm 0.90$ \\
\hline $\begin{array}{l}\text { Low shear-rate of total blood } \\
\text { reductive viscosity }(3 / \mathrm{s})\end{array}$ & $15.99 \pm 2.02$ & $16.67 \pm 2.2$ \\
\hline $\begin{array}{l}\text { erythrocyte } \\
\text { sedimentationrate(ESR) }\end{array}$ & $7.13 \pm 2.03 * *$ & $11.25 \pm 2.12$ \\
\hline
\end{tabular}

Note: as compared with subjects in the control group, who have winter swimming $* \mathrm{p}<0.05 * * \mathrm{p}<0.01$

\section{DISCUSSION}

Swimming in cold water during the winter season is an extreme sport, with fans all over the world. However, its effects on health have been debated.Blood is prone to be concentration, viscosity and coagulation with the increase of age.Reduction of blood viscosity and plasma viscosity to lower the aggregation of erythrocytes and improve deformability of erythrocytes and lower the contents of fibrinogen,by keeping negative charge level on RBC Surface to antigravity field.

Analysis on influences of long -term winter swimming on hemorheology of males (70-80 years old ) were made by above indexes. Consult health examination archives of subjects since 1998 ,and then comparison and analysis of all lipid and hemorheology indexes were made. The obtained primary data were processed by SPSS12.0 statistics software. The whole-blood viscosity at low, medium and high shear of winter swimming group, the reduced viscosity of whole blood is lower than that of control group, viscosity of whole blood is 
higher than that of control group; There was no significance difference. Two groups of hematocrit means are equal. The plasma viscosity and erythrocyte sedimentation rate (ESR) of winter swimming group was obviously lower than those of the control group, there's obvious difference $(\mathrm{P}<0.01)$. A long term winter swimming can reduce the blood plasma viscosity and erythrocyte sedimentation rate (ESR) of the male (70-80 years old), improve hemorheology characteristics.

It provides scientific exercises prescription for training practice.try to gives guidance of exercise rehabilitation to the depressive patients by means of exercise prescriptions. In order to support that physical exercise can treat depression,it should be considered comprehensively from the pattern, intensity and lasting duration of exercise when establishing the exercise prescription, and then obtain the scientific and reasonable exercise prescription in the medical supervision.

\section{ACKNOWLEDGMENT S}

I express our appreciation to the subjects for their time and efforts. This investigation was made possible by generous support from the Association of Taian Winter Swimming, Taian Colliery Sanitarium.

\section{REFERENCES}

[1] Cerasola G,Cottone S,Mule G,et al. Microalbuminuria, renaldysfunction and cardiovascular complication in essential hyper-tension[J].J Hypertens, 1996,14(7):915-920.

[2] Berg A. I,et.al. Physical activity and lipoprotein lipid disorders [J]Sport Med,1994,17:6 21.

[3] .Paula C Sowers JR. Relation between lipids and atherosclerosis;epidemiologic evidence and clinical im-plications AM J cardio, 1990;66(21):71.

[4] Zhao Shui-ping, Wang Zhong-lin, Lu Zong-liang. Clinical blood lipidlogy.[M].Changsha: Hunan Science \& Technology Press (Chin), 1997.

[5] Olli, T.R artakari,et.al.Associations between physical activity and risk factors for coronary heart disease[J]. T he cardiovascular Risk Young Finns Study, Med.Sci.Sports.Exerc1997,29(8):1055-1061.
[6] Berg A.I,et.al.Physical activety and lipopotein lipid disorder sport[J].Med.1994,17:6-21.

[7] ZHANG Yi-long, WANG Hong-xiang .Study of Effets of Taijiquan Exercises on Blood Serum Lipoprotein and Level of Apolipoprotein[J]. Journal of Physical Education Institute of Shanxi Teachers University. 2006,21(1):120-122.

[8] NP Pronk, SF Crouse, BC O'Brien, and JJ Rohack. Acute effects of walking on serum lipids and lipoproteins in women.[J] Sports Med Phys Fitness. 1995; 35(1): 50-58.

[9] Wang Song-tao,Wang An-li,Wang Zheng-zhen, et al. Comparisons of Influence of walking of different intensities on the Body composition and lipid in elderly men $[\mathrm{J}]$. Chinese Journal of Sports Medicine,2005,24(5):599-602.

[10] Li Hua. winter swimming[M].Beijing:Jincheng publish house.2004,2166.

[11] Michael A.Ferguson, Nathan L. Alderson, StewartG. Trost, David A. Essig, R. Burke, and J.Larry Durstine. Effects of four different single exercise sessions on lipids, lipoproteins, and lipoprotein lipase. J.Appl. Physiol.1998, 85(3): 1169-1174.

[12] Weng Wei-liangh. Methodology of Hemorheology and Its Application [M]. Beijing: Science Press.1989.

[13] Wang Wei-qun,Huang Min. Effects of excise on blood rheology of the ederly [J]. Chinese Journal of Sports Medicine.1996,15(2):154.

[14] Sun Xiao-min,Zeng Qian. The Effect of Blood Circulation and Fat Metabolism on Old Men Playing Croquet [J]. Journal of Guangzhou Sport University. 1997,17(4):37-40.

[15] Guo Shou-jing, Lu Chuan-sheng. A Comparative Study on the effects of Taiji and Croquet on blood rheology and blood of the elderly [J]. Journal of Clinical Rehabilitative Tissue Engineering Research. 2002.6(23):35-65.

[16] Ni Hong-ying,Lei Xiang-Shen,et al. Effects of one acute 24 style Taiji exercises on cardiovascular function and blood of senior intellectuals [J]. Chinese Journal of Sports Medicine.2001,20(1):76.

[17] Yao Yong. Effects of winter swimming on blood rheology and Microcirculation in middle-aged and elderly people o [J]. Chinese Journal of Gerontology. 1992,12(5):293-295

[18] Zhou Jin-hua,Guo Zhi-rong,Yao Yong,et al. Effects of winter swimming on blood rheology of the elderly [J]. Chinese Journal of Sports Medicine .1995,14(1):44-46.

[19] HE Ying,LU Rong-zhong. The Relationship between ESR and Hematocrit Intercurrent Composition [J]. Chinese Journal of Hemorheology.2001,11(4):289-291 